\title{
Bathymetry Estimation Using the Gravity-Geologic Method: An Investigation of Density Contrast Predicted by the Downward Continuation Method
}

\author{
Yu-Shen Hsiao ${ }^{1,}$, Jeong Woo Kim ${ }^{1}$, Kwang Bae Kim ${ }^{1}$, Bang Yong Lee $^{2}$, and Cheinway Hwang ${ }^{3}$ \\ ${ }^{1}$ Department of Geomatics Engineering, University of Calgary, Calgary, Canada \\ ${ }^{2}$ Korea Polar Research Institute, Korea Ocean Research and Development Institute, Incheon, Korea \\ ${ }^{3}$ Department of Civil Engineering, National Chiao Tung University, Hsinchu, Taiwan
}

Received 31 March 2010, accepted 13 October 2010

\begin{abstract}
The downward continuation (DWC) method was used to determine the density contrast between the seawater and the ocean bottom topographic mass to estimate accurate bathymetry using the gravity-geologic method (GGM) in two study areas, which are located south of Greenland (Test Area \#1: $40-50^{\circ} \mathrm{W}$ and $50-60^{\circ} \mathrm{N}$ ) and south of Alaska (Test Area \#2: 140 $150^{\circ} \mathrm{W}$ and $\left.45-55^{\circ} \mathrm{N}\right)$. The data used in this study include altimetry-derived gravity anomalies, shipborne depths and gravity anomalies. Density contrasts of 1.47 and $1.30 \mathrm{~g} \mathrm{~cm}^{-3}$ were estimated by DWC for the two test areas. The considerations of predicted density contrasts can enhance the accuracy of $3 \sim 4 \mathrm{~m}$ for GGM.

The GGM model provided results closer to the NGDC (National Geophysical Data Center) model than the ETOPO1 (Earth topographical database 1) model. The differences along the shipborne tracks between the GGM and NGDC models for Test Areas \#1 and \#2 were 35.8 and $50.4 \mathrm{~m}$ in standard deviation, respectively. Furthermore, these differences were more strongly correlated with gravity anomalies than bathymetry in the test areas. It is shown that an accuracy of under $40 \mathrm{~m}$ can be obtained with comparisons to shipborne depths only in Test Area \#1.
\end{abstract}

Key words: Gravity-geologic method, Density contrast, Downward continuation

Citation: Hsiao, Y. S., J. W. Kim, K. B. Kim, B. Y. Lee, and C. Hwang, 2011: Bathymetry estimation using the gravity-geologic method: An investigation of density contrast predicted by the downward continuation method. Terr. Atmos. Ocean. Sci., 22, 347-358, doi: 10.3319/TAO.2010.10.13.01(Oc)

\section{INTRODUCTION}

Estimating accurate bathymetry is important for understanding many of the Earth's physical properties. For geodesists, it is useful for investigations of currents, tides and the sea floor topography; and, for geophysicists, bathymetry is helpful to understanding the characteristics of the Earth's interior sources. In addition, bathymetry can be used to figure out the shape and evolution of the Earth. Although shipborne sonar sounding provides better spatial resolution along shipborne tracking, coverage is severely limited. Therefore, in addition to shipborne measurements, satellite altimetry-derived gravity anomalies are often used to determine bathymetry, particularly in remote areas such as the Arctic Ocean.

One of the geophysical methods for predicting bathymetry is the gravity-geologic method (GGM), which was

\footnotetext{
* Corresponding author

E-mail:geo.yshsiao@gmail.com
}

originally developed for predicting the depth to basement overlain by lower density glacial drift deposits (Ibrahim and Hinze 1972). This method can be readily applied in estimating bathymetry with sparse known shipborne depth values and altimetry-derived gravity (Kim et al. 2011). Compared to other methods, the advantage of GGM lies in its suitability for large-scale areas.

A number of studies based on GGM have been carried out, e.g., Adams and Hinze (1990), Nagarajan (1994), Mossler (1998), Chandler (2000) and Kim et al. (2011). Most of the results show bathymetry with an accuracy of $20 \sim 40 \mathrm{~m}$, validated by shipborne measurements. In GGM, determination of the best density between the seawater and the ocean floor mass is a key factor for obtaining an accurate bathymetric model.

In general applications of GGM, it is assumed that the density contrast between seawater and bedrock is roughly $1.64 \mathrm{~g} \mathrm{~cm}^{-3}$, which is the mean density difference between 
bedrock $\left(2.67 \mathrm{~g} \mathrm{~cm}^{-3}\right)$ and seawater $\left(1.03 \mathrm{~g} \mathrm{~cm}^{-3}\right)$. However, recent studies have taken into consideration many methods to determine the real density contrast by observations, e.g., Cordell (1973), Chai and Hinze (1988), Bhaskara Rao et al. (1990), Ramillien and Cazenave (1997), Hwang (1999), Strykowski et al. (2005), Silva et al. (2006) and WildPfeiffer (2008). One of these techniques is the downward continuation (DWC) method. In general, downward (or upward) continuation is a technique that can be used to transform the gravity potential or field of a surface onto that of a lower/higher surface (Blakely 1995). Thus, DWC is useful in converting the surface gravity field, in particular, to the reference level in which we are interested.

The scale between two levels of gravity fields can be computed and adopted to estimate density contrasts, with the assumption that the gravity variations are caused by the undulation of the ocean floor. In this study, we considered the influence of the topographic effect before using DWC to make the space empty. The method for computing topographic gravity effect was the prism method, which has been discussed in detail by St John and Green (1967), Forsberg (1984) and Hwang et al. (2003) and has been proven to be a useful technique to solve the problems of topographic effects.

The objective of this study is to apply our GGM approach to estimate more accurate bathymetry by determining the density contrast between the seawater and the ocean bottom topography. To this end, DWC was applied in predicting the density contrasts in two study areas: south of Greenland $\left(40-50^{\circ} \mathrm{W}\right.$ and $\left.50-60^{\circ} \mathrm{N}\right)$ and south of Alaska $\left(140-150^{\circ} \mathrm{W}\right.$ and $\left.45-55^{\circ} \mathrm{N}\right)$. Finally, we used global bathymetric models and selected shipborne measurement data to validate the GGM estimated models by comparing their statistics.

\section{METHODOLOGY}

\subsection{The Gravity-Geologic Method (GGM)}

The strategy of predicting bathymetry in this study is based on the gravity-geologic method (GGM) developed by Ibrahim and Hinze (1972). The observed gravity measurement can be divided into the short- and long-wavelength gravity. It can be given by:

$\Delta g_{\text {obs }}(i)=\Delta g_{\text {short }}(i)+\Delta g_{\text {long }}(i)$

where $\Delta g_{\text {obs }}(i)$ means observed gravity field, and $\Delta g_{\text {short }}(i)$ and $\Delta g_{\text {long }}(i)$ denote short- and long-wavelength gravity fields, respectively.

The short-wavelength gravity field is derived from variations of local bedrock topography, and the long-wavelength gravity is generated by deeper mass variations. Figure 1 illustrates the geometries of GGM. The points $j_{1,2 \ldots k}$ indicate the shipborne measurements that were used to generate the short-wavelength gravity. The equation can be given by the Bouguer plate formula:

$\Delta g_{\text {short }}(j)=2 \pi G \Delta \rho[E(j)-D]$

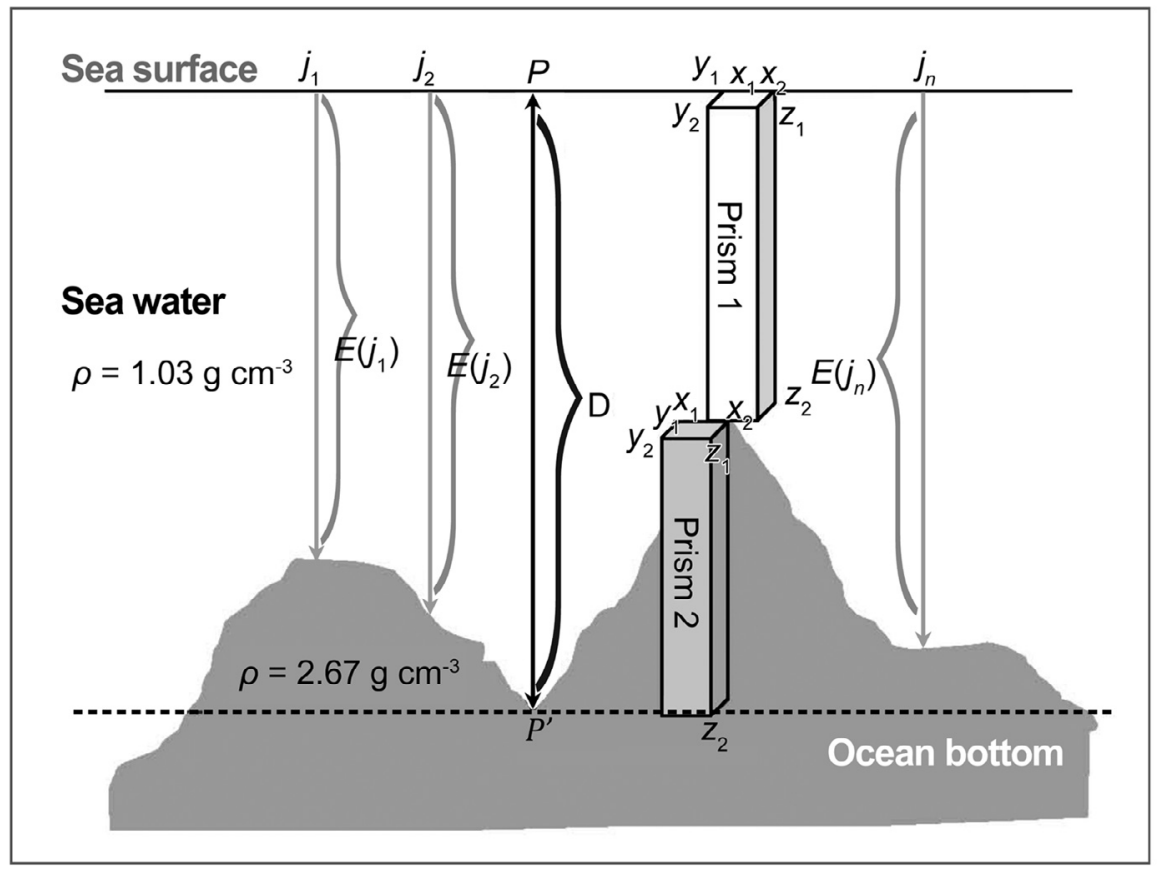

Fig. 1. The geometries of GGM. 
where $\Delta g_{\text {short }}(j)$ denotes the short-wavelength gravity at the $j$-th point; $G$ is a gravitational constant, $6.672 \times 10^{-8} \mathrm{~cm}^{3}$ $\mathrm{g}^{-1} \sec ^{-2} ; \Delta \rho$ is the density contrast between seawater and bedrock; $E(j)$ is the depth at the $j$-th point; and, $D$ is the reference datum elevation, which is usually referenced to the deepest depth of the control points.

Furthermore, $\Delta g_{\text {short }}(j)$ can be subtracted from the observed gravity, $\Delta g_{o b s}(j)$, to obtain the long-wavelength gravity, $\Delta g_{\text {long }}(j)$, at the $j$-th point. After that, $\Delta g_{\text {long }}(j)$ can be interpolated to create a grid of the long-wavelength gravity field, $\Delta g_{\text {long }}(i)$, which represents mass variations under the datum elevation, $D$. Then, $\Delta g_{\text {long }}(i)$ is removed from the observed gravity field, $\Delta g_{o b s}(i)$; and, the short-wavelength gravity field, $\Delta g_{\text {short }}(i)$, can be obtained. Once the shortwavelength gravity are estimated, they are subsequently transformed into estimates of the depths to bedrock, which are given by:

$E(i)=\frac{\Delta g_{\text {short }}(i)}{2 \pi G \Delta \rho}+D$

where $E(j)$ is a grid of an estimated bathymetric model estimated by GGM.

The factors influencing the accuracy of the GGM bathymetric model include (1) the accuracy of $\Delta g_{\text {long }}(j)$, $\Delta g_{\text {obs }}(j)$ and $\Delta g_{\text {short }}(j)$; (2) the number and distribution of elevation control points (i.e., if the control points are denser and more numerous, the predicted bathymetry of shortwavelengths are more representative); and (3) the density contrast, $\Delta \rho$. In this paper, the depth and gravity values at the $j$-th point $\left[E(j)\right.$ and $\left.\Delta g_{o b s}(j)\right]$ are derived from shipborne measurements because they are more accurate, and the observed gravity fields $\left[\Delta g_{o b s}(i)\right]$ are altimetry-derived because of the data coverage.

\subsection{Downward Continuation (DWC) Method}

The values of density contrast $\Delta \rho$ mentioned in section 2.1 would be determined by downward continuation (DWC). In general, continuation methods in the potential field are derived from the integral Poisson formula (Heiskanen and Moritz 1967) and they are divided into upward continuation (UWC) and DWC operations; however, their characteristics are different. UWC is a smooth operation that is characterized as a well-posed problem, whose solution is unique; whereas, DWC is an unstable operation that is characterized as an ill-posed problem, making solutions non-unique (Tikhonov and Arsenin 1977).

In this study, DWC was readily implemented by the Fast Fourier transform (FFT) technique. In comparison with other algorithms, the obvious advantage of FFT is its rapid computation, but the unavoidable edge effects and cyclic convolution should be eliminated carefully by $100 \%$ zero padding. UWC from the gravity field at the $z=h_{1}$ plane to the $z=h_{2}$ plane can be expressed in the wavenumber domain as in (Parker 1977):

$G_{h_{2}}\left(f_{x}, f_{y}\right)=e^{-2 \pi \Delta h_{12} \sqrt{f_{x}^{2}+f_{y}^{2}}} G_{h_{1}}\left(f_{x}, f_{y}\right)$

where $G_{h_{1}}\left(f_{x}, f_{y}\right)$ and $G_{h_{2}}\left(f_{x}, f_{y}\right)$ denote the two-dimensional Fourier transforms of the gravity field at $h_{1}$ and $h_{2}$, respectively; $f_{x}$ and $f_{y}$ represent the horizontal frequency in $\mathrm{x}$ and $\mathrm{y}$ components, respectively; and, $\Delta h_{12}=h_{2}-h_{1}$.

In contrast to UWC, the wavenumber response function of DWC from the gravity field at the $\mathrm{z}=h_{2}$ plane to the $\mathrm{z}=h_{1}$ plane is given by (Parker 1977):

$G_{h_{1}}\left(f_{x}, f_{y}\right)=e^{2 \pi \Delta h_{12} \sqrt{f_{x}^{2}+f_{y}^{2}}} G_{h_{2}}\left(f_{x}, f_{y}\right)$

DWC by FFT is essentially a high-pass filtering operation that amplifies the short-wavelength signals, especially noise. In order to alleviate the noise, a filtering or smoothing technique should be applied to the FFT DWC method. Thus, Eq. (5) becomes:

$G_{h_{1}}\left(f_{x}, f_{y}\right)=e^{2 \pi \Delta h_{12} \sqrt{f_{x}^{2}+f_{y}^{2}}} G_{h_{2}}\left(f_{x}, f_{y}\right) F\left(f_{x}, f_{y}\right)$

where $F\left(f_{x}, f_{y}\right)$ is a low-pass filter in the wavenumber domain.

In this study, a simple Guassian low-pass filter was used. The Gaussian filter has a number of desirable properties that make it the most commonly used smoothing filter. For example, the Gaussian filter is the only low-pass filter that has good localization properties in both the spatial and frequency domains; and, it is decomposable and rotationally invariant. Moreover, Gaussian filters are closely related to the techniques of multi-resolution or multi-scale processing, because they can be employed to create input data with varying resolutions, ranging from coarse to fine. The transfer function of the Gaussian filter (for equally spaced and weighted measurements) is:

$F_{\text {Gau }}\left(f_{x}, f_{y}\right)=e^{k^{2}\left(\sqrt{f_{x}^{2}+f_{y}^{2}}\right)^{2}}$

where $k$ is the semi-bandwidth of the Gaussian function in the frequency domain and dominates the resolutions of the DWC results.

The smoothed DWC gravity using the Gaussian filter is expressed as:

$G_{h_{1}}\left(f_{x}, f_{y}\right)=G_{h_{2}}\left(f_{x}, f_{y}\right) e^{2 \pi \Delta h_{12} \sqrt{f_{x}^{2}+f_{y}^{2}}-k^{2}\left(\sqrt{f_{x}^{2}+f_{y}^{2}}\right)^{2}}$

The Gaussian filter is used to eliminate high frequency noise due to the ill-posed problem; however, the risk in cancelling 
high frequency noise is to truncate useful signals. Thus, the selection of $k$ needs to be a compromise between noise reduction and signal preservation.

\subsection{Computation of Topographic Gravity Effect}

We considered the influence of the topographic gravity effect before using DWC, because DWC technique is only implemented in a harmonic domain, which means an empty space. The integration of topographic effects by prisms is a method of space-domain computations. In this method, the topographic gravity effect at $P$ (in Fig. 1) due to a rectangular prism bounded by $\left[x_{1}, x_{2}\right],\left[y_{1}, y_{2}\right],\left[z_{1}, z_{2}\right]$ is given by ( $\mathrm{St}$ John and Green 1967):

$$
\begin{aligned}
& T=G \rho \iiint \frac{z}{r^{3}} d v=G \rho \| x \ln (y+r)+y \ln (x+r) \\
& -z \tan ^{-1}\left[\frac{z^{2}+y^{2}+y r}{(y+r) \sqrt{y^{2}+z^{2}}}\right] \mid \begin{array}{l|l|l}
x_{2} & y_{2} \\
x_{1} & z_{1} & z_{2} \\
z_{1}
\end{array}
\end{aligned}
$$

where $x$ and $y$ are the horizontal coordinate components, $z$ is the vertical coordinate (also elevation in this case), and $r=\sqrt{x^{2}+y^{2}+z^{2}}$.

We computed the gravity effects of the prisms with a density of $1.03 \mathrm{~g} \mathrm{~cm}^{-3}$ between the sea surface and the ocean bottom (see "Prism 1" in Fig. 1) and with a density of $2.67 \mathrm{~g} \mathrm{~cm}^{-3}$ between the ocean bottom and the surface of $P^{\prime}$ (see "Prism 2" in Fig. 1). The total topographic effect is obtained by summing the contributions from all prisms. The topographic gravity effect at $P$ is removed prior to the DWC computation, and the topographic gravity effect at $P^{\prime}$ is then restored to achieve downward-continued gravity.

\section{TEST AREAS AND DATA}

Figure 2a presents distributions of shipborne tracks of the National Geophysical Data Center (NGDC) of the National Oceanic and Atmospheric Administration (NOAA) (http://www.ngdc.noaa.gov/mgg/geodas/trackline.html). The background denotes bathymetry from Earth topographical database 1 (ETOPO1) (Amante and Eakins 2008). ETOPO1 is a global heterogeneous bathymetric-topographic model with spacing of 1 arc minute.

The two gray rectangles in Fig. 2a denote Test Areas \#1 and \#2. Test Area \#1 is located south of Greenland between $40-50^{\circ} \mathrm{W}$ and $50-60^{\circ} \mathrm{N}$. The range of bathymetric variation is between 0 and 4604 meters below sea level. There is some land mass in the northern part of the area, which is masked out. Test Area \#2 is located south of Alaska between $140-150^{\circ} \mathrm{W}$ and $45-55^{\circ} \mathrm{N}$. Although the deepest depth in Test Area \#2 reaches 5379 m below sea level, the gradient of bathymetry is smaller than that of Test Area \#1.

Figures $2 \mathrm{~b}$ and $3 \mathrm{c}$ represent shipborne track distribu- (a)

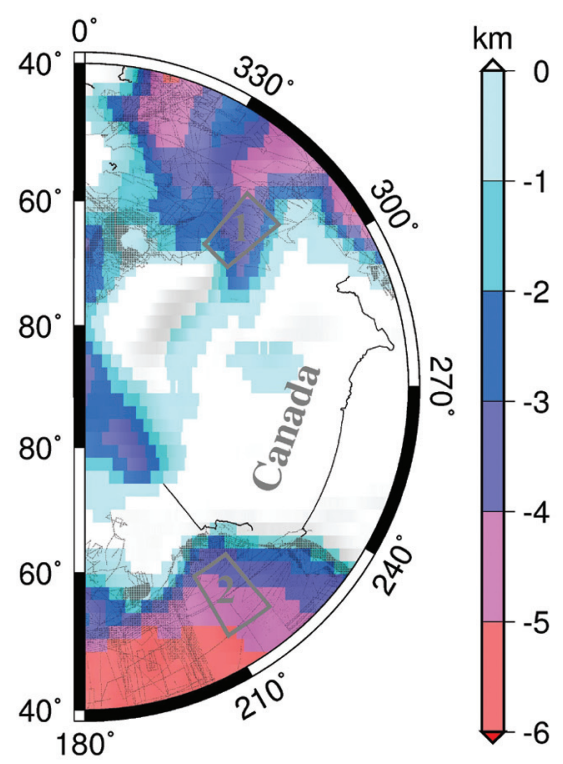

(b)

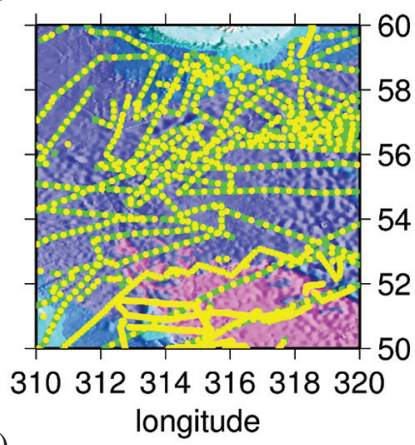

c)

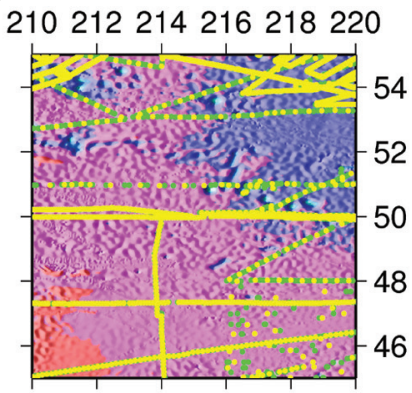

Test Area \#2 (d) Test Area \#1

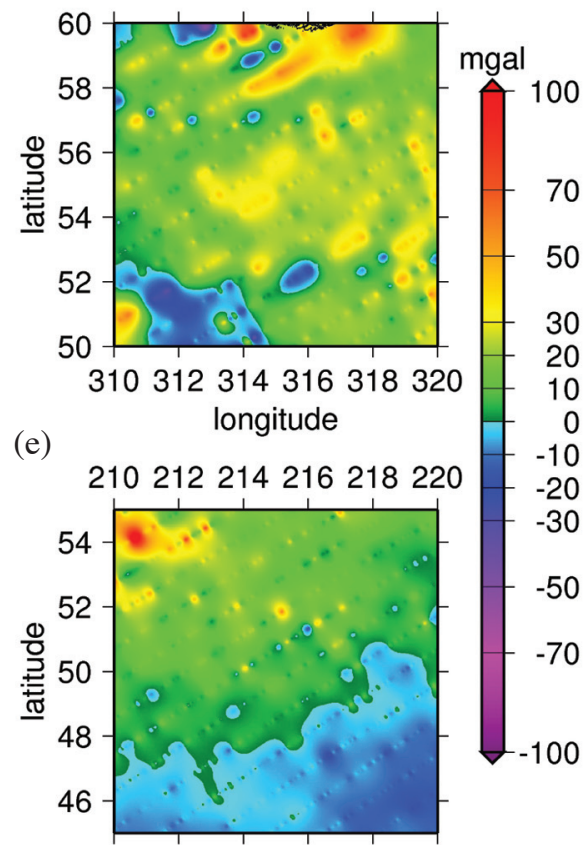

Test Area \#2

Fig. 2. (a) Distributions of NGDC shipborne tracks from latitudes 40 to $90^{\circ} \mathrm{N}$ and longitudes 0 to $180^{\circ} \mathrm{W}$. The background denotes bathymetry of ETOPO1. The two grey rectangles indicate Test Areas \#1 and \#2. The green and yellow dots in zoom-in views of (b) Test Area \#1 and (c) Test Area \#2 mean control and check points. (d) (e) Free-air gravity anomalies in Test Areas \#1 and \#2. 
tions in Test Areas \#1 (5420 points) and \#2 (4680 points), respectively. All shipborne data contained gravity and depth measurements. In the crossover analysis of gravity observations for shipborne tracks, the standard deviation in Test Areas \#1 and \#2 are 2.6 and 2.9 mgals after bias and drift corrections. The order of accuracy of shipborne data could be accepted by GGM predictions. Green and yellow dots denote the control and check points, respectively. The control points were used to create a long-wavelength gravity field in GGM [Eq. (2)], and the check points evaluated the accuracy of the bathymetric estimates. In order to stagger the control and check points, two-thirds of the shipborne data were picked for the control points and the remaining third for the check points. With every third point of a ship track selected as check points, the control points were distributed identically to the check points.

In this study, we picked 3615 of total ship-derived data for the control points and 1805 for the check points in Test Area \#1. For Test Area \#2, 3114 and 1566 of total shipborne data were used for the control and check points, respectively (Figs. 2b and c). Overall, the shipborne measurement points were denser and better distributed in Test Area \#1 than in Test Area \#2.

(a)

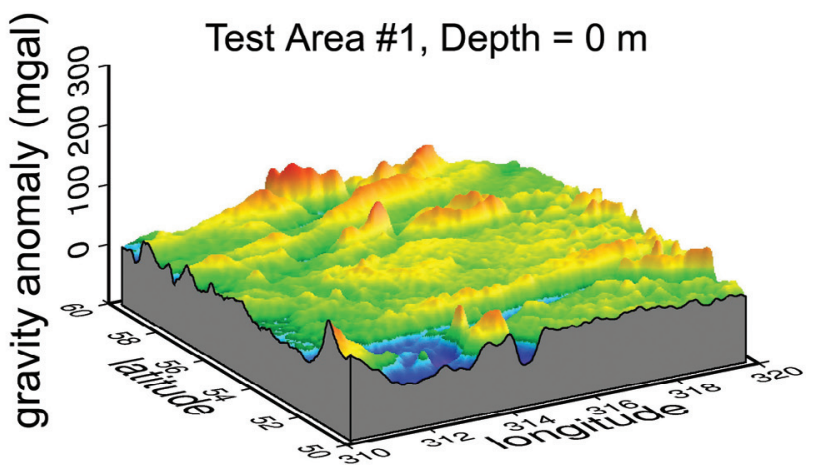

(c)

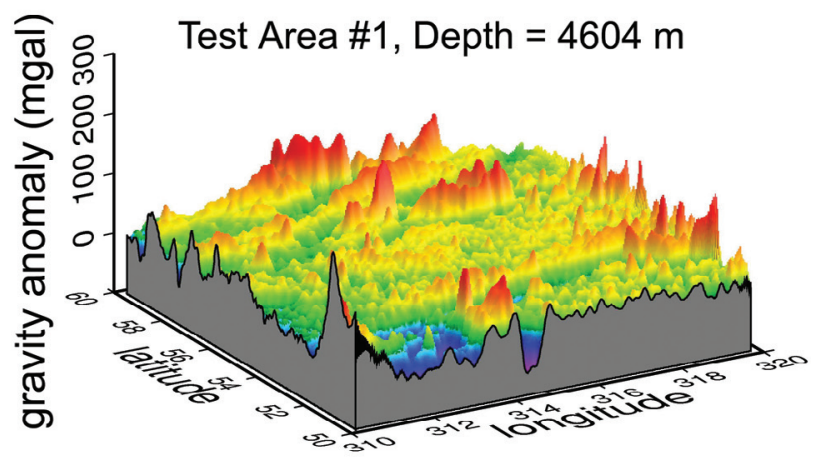

Figures $2 \mathrm{~d}$ and e illustrate the 1 arc minute free-air gravity anomalies in Test Areas \#1 and \#2, respectively, which were extracted from the Scripps Institution of Oceanography (SIO), University of California, San Diego. However, the resolution of the original grid from SIO was not exactly 1 arc minute, due to map projection that distorts the grid at high latitude areas. Thus, the original data were regridded to real 1 arc minute resolution by using harmonic interpolation with the Generic Mapping Tools (GMT) package (Wessel and Smith 1995).

There were, in total, 361201 points in the SIO dataset for the two test areas. Gravity anomalies in both test areas were within $\pm 100 \mathrm{mgal}$. The gravity gradient in Test Area \#1 was generally bigger than that in Test Area \#2. In the north of Test Area \#1, which is a shallow water area, the gravity anomalies became huge. The gravity anomalies in Test Area \#2 were mostly moderate; however, they became larger over the northwest area, reaching values of approximately $70 \mathrm{mGal}\left(1 \mathrm{Gal}=1 \times 10^{-2} \mathrm{~m} \mathrm{sec}^{-2}\right)$.

Overall, the differences of the variations of bathymetry and gravity in the two test areas were not huge. The greatest discrepancies between Test Areas \#1 and 2 were the amount and distribution of shipborne tracks. (b)

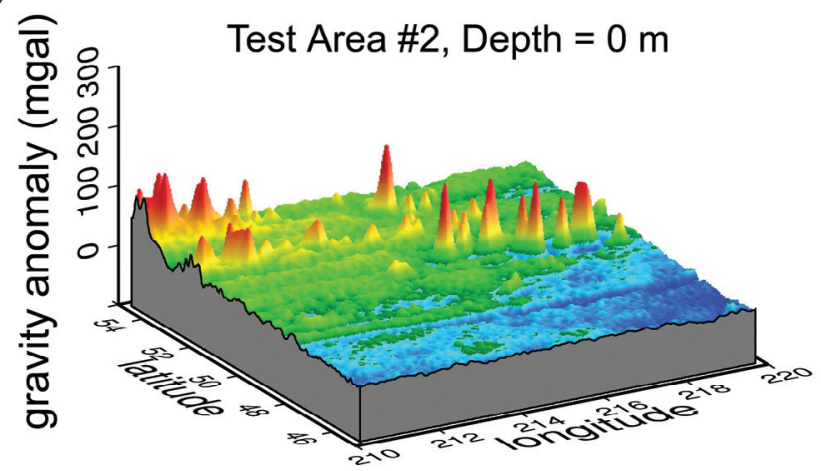

(d)

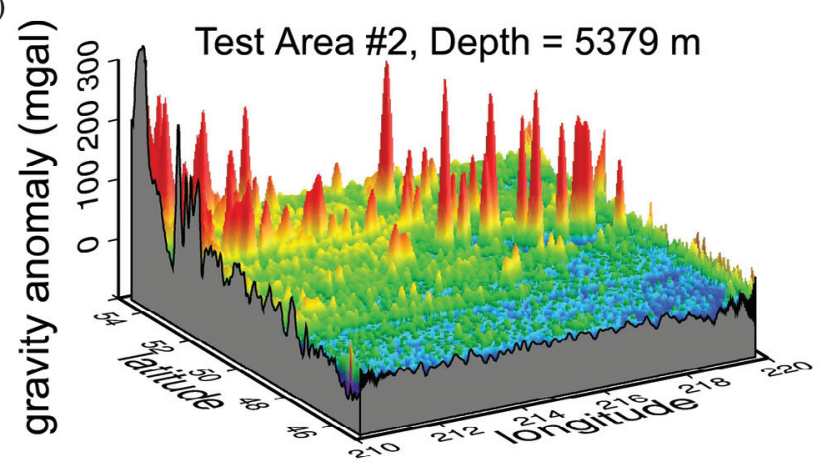

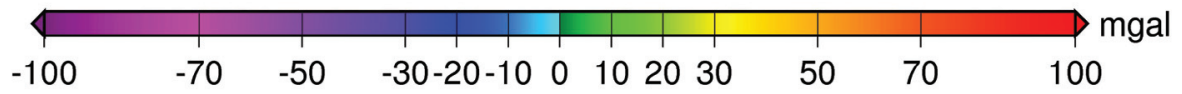

Fig. 3. Gravity anomalies at sea in (a) Test Areas \#1 and (b) Test Area \#2, and downward-continued gravity anomalies at the bottom surfaces of (c) Test Areas \#1 and (d) Test Area \#2. 


\section{DETERMINATION AND RESULTS OF DENSITY CONTRASTS}

The ratio between the original and downward-continued gravity anomalies, which are located at sea level and the surface of $P^{\prime}$ (see Fig. 1), respectively, was computed and used to predict the density contrast. The density contrasts were calculated to the deepest depths of 4604 and $5379 \mathrm{~m}$ in Test Areas \#1 and \#2, respectively.

In addition to considering the topographic effect, the geopotential-derived gravity effect should be also taken into account before applying DWC, in order to remove longwavelength gravity effects. In areas with complex topography, it is very important to adopt the removal procedure, because it makes the values for these areas smoother and more representative. After DWC, the geopotential-derived gravity effect can be restored into the DWC signals. In this study, we adopted the Earth Gravitational Model 2008 (EGM2008) (Pavlis et al. 2008) spherical harmonic coefficients, expanding to degree and order 360 , which is suitable to represent the long-wavelength gravity effects for DWC (Hsiao and Hwang 2010).

In addition, Hsiao (2007) suggested that the Gaussian filter with a wavenumber of $0.1 \mathrm{~m}^{-1}$ be the trade-off between noise reduction and gravity signal preservation, which has been proven to be the optimal width at the distance of approximately $5000 \mathrm{~m}$ in DWC. Thus, we chose the wavenumber of $0.1 \mathrm{~m}^{-1}$ for the Gaussian filter for the two test areas.

The procedure of DWC involves the following steps:

(1) Remove topographic and EGM2008-derived gravity effects from the original gravity field to obtain a residual field.

(2) Downward continue the residual field from the sea surface to the surface of the deepest depth.
(3) Restore topographic and EGM2008-derived gravity effects into the downward-continued residual field to acquire a downward-continued gravity field.

Figure 3 shows the gravity field before and after DWC in the two test areas, and it clearly reveals that the downwardcontinued gravity fields are much stronger than the original gravity fields. Comparing the scales of the two fields in Test Areas \#1 and \#2, respectively, $\Delta \rho=1.47 \mathrm{~g} \mathrm{~cm}^{-3}$ for Test Area \#1 and $\Delta \rho=1.30 \mathrm{~g} \mathrm{~cm}^{-3}$ for Test Area \#2 were the predicted density contrasts at the deepest depths and were applied to the GGM bathymetry predictions. Although the maximum depth in Test Area \#1 was less than that of Test Area \#2, the predicted density contrast in Test Area \#1 is larger. The reason is that the gravity field of Test Area \#2 was more moderate than that of Test Area \#1. Furthermore, the predicted density contrasts were both smaller than the geologically reasonable density contrast of $1.67 \mathrm{~g} \mathrm{~cm}^{-3}$.

\section{RESULTS OF BATHYMETRY PREDICTIONS AND ACCURACY ANALYSES}

Figures 4 through 6 and Tables 1 and 2 present the results from Test Area \#1; and Figs. 7 through 9 and Tables 3 and 4 from Test Area \#2. Figure 4 presents the bathymetric models of GGM and the differences of bathymetric models between GGM and ETOPO1, GGM and NGDC, and ETOPO1 and NGDC. NGDC model was gridded from NGDC ship-derived measurements. Table 1 denotes the statistics and correlation coefficients between the three bathymetric models. The statistics of the differences are summarized in Table 2. The differences between the GGM and NGDC models and the GGM and ETOPO1 models reached approximate standard deviations of 39.4 and $229.6 \mathrm{~m}$, respectively.

\section{Test Area \#1}

(a) GGM

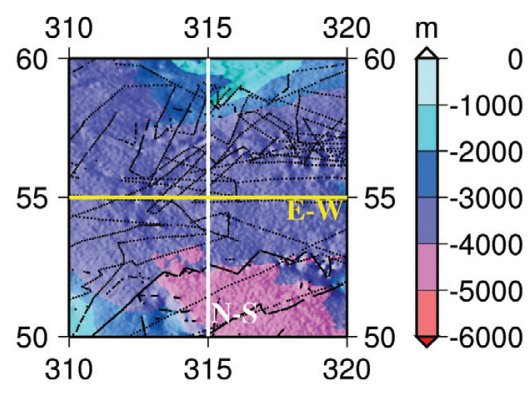

(b) GGM-ETOPO1

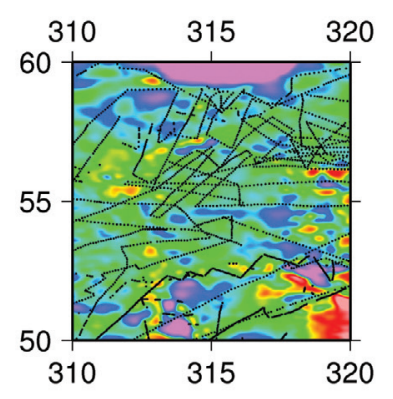

(c) GGM-NGDC

(d) ETOPO1-NGDC
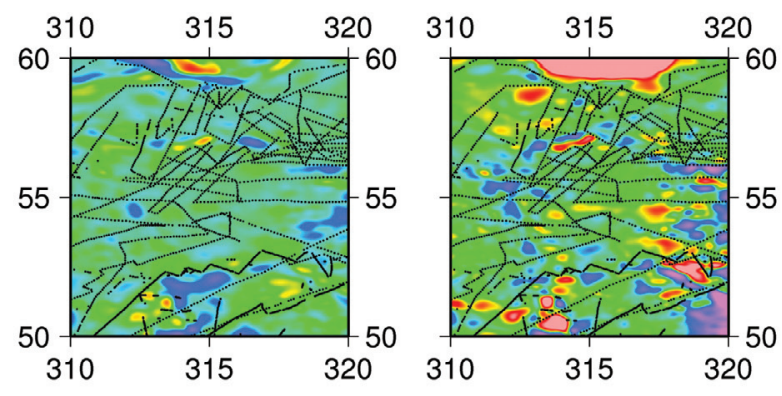

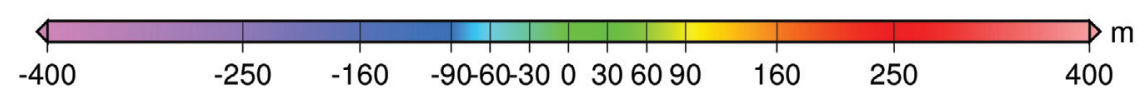

Fig. 4. Test Area \#1. GGM bathymetric models (a) and differences of bathymetric models between (b) GGM and ETOPO1, (c) GGM and NGDC, and (d) ETOPO1 and NGDC. 
The differences shown in Figs. $4 b$ and $d$ are obviously larger than those in Fig. 4c, indicating that the results of the GGM model were much closer to those of the NGDC model. The largest differences in Figs. $4 \mathrm{~b}$ and $\mathrm{d}$ are located in the northern portion of Test Area \#1, which is a shallow water area. The huge differences in values over the area can reach approximately $\pm 900 \mathrm{~m}$. A large part of these significant differences can be attributed to the steep sea topography and sparse ship-derived data. Thus, GGM cannot accurately predict bathymetric values in this area. On the other hand, the differences in Fig. 4c are relatively slight, and the extreme differences are only $\pm 200 \mathrm{~m}$. The correlation coefficients in Table 1 are in good agreement with the small differences between the GGM and NGDC models.

Figure 5 shows the bathymetric profiles along the longitude of $45^{\circ} \mathrm{W}$ and the latitude of $55^{\circ} \mathrm{N}$ (See Fig. 4a). The big differences located in the north of Figs. $4 \mathrm{~b}$ and $6 \mathrm{~d}$ were on the north-south profile, which passes through the shallow water area. Therefore, there were inconsistencies occurring after the latitude of $59^{\circ} \mathrm{N}$ in Fig. $5 \mathrm{a}$.

Table 1. Comparisons of statistics and correlation coefficients between the GGM, ETOPO1, and NGDC bathymetric models in Test Area \#1 (unit: meter).

\begin{tabular}{|c|c|c|c|c|c|c|c|}
\hline \multirow{2}{*}{ Model } & \multirow{2}{*}{ Max } & \multirow{2}{*}{ Min } & \multirow{2}{*}{ Mean } & \multirow{2}{*}{ Std Dev } & \multicolumn{3}{|c|}{ Correlation Coefficient } \\
\hline & & & & & GGM & ETOPO1 & NGDC \\
\hline GGM & -934.1 & -4447.1 & -3369.9 & 617.6 & - & 0.92 & 0.98 \\
\hline ETOPO1 & 0.0 & -4604.1 & -3314.2 & 742.7 & 0.92 & - & 0.91 \\
\hline NGDC & -918.4 & -4441.4 & -3346.4 & 616.4 & 0.98 & 0.91 & - \\
\hline
\end{tabular}

Table 2. Statistics of differences (in m) between GGM and ETOPO1, GGM and NGDC, ETOPO1 and NGDC in Test Area \#1.

\begin{tabular}{ccccc}
\hline Models & Max & Min & Mean & Std Dev \\
\hline GGM - ETOPO1 & 435.7 & -934.1 & -46.4 & 229.6 \\
GGM - NGDC & 230.1 & -264.2 & 12.2 & 39.4 \\
ETOPO1 - NGDC & 918.4 & -501.4 & 41.3 & 245.0 \\
\hline
\end{tabular}

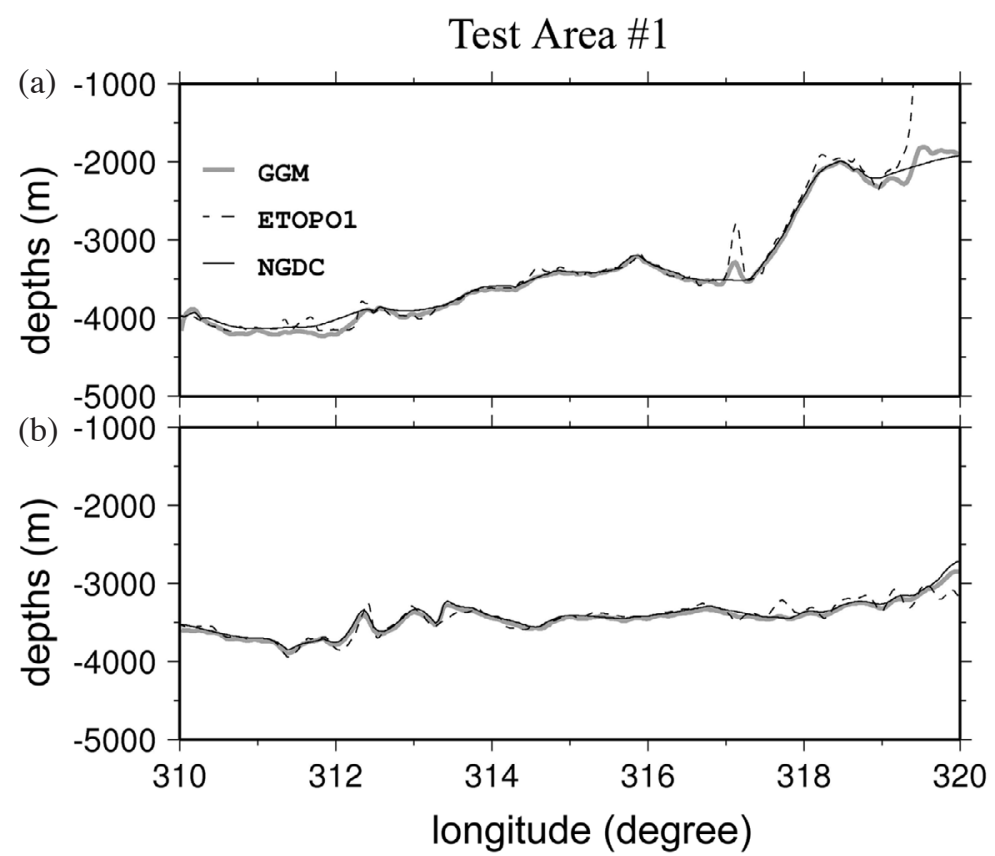

Fig. 5. Test Area \#1. Comparisons for bathymetry along the (a) longitude of $45^{\circ} \mathrm{W}$ and (b) latitude of $55^{\circ} \mathrm{N}$. 
The GGM model was interpolated to the locations of the check points of NGDC shipborne tracks, in order to compare it with NGDC shipborne measurements. Figure 6a shows the differences between them at the locations of shipborne tracks. Most differences were small, except for several points over the south. A histogram is displayed in Fig. $6 \mathrm{~b}$ for statistics. In order to determine the reason for the big differences, the relationships between the differences and the bathymetry and gravity were analyzed and are shown in Figs. $6 \mathrm{c}$ and d, respectively. According to Figs. $6 \mathrm{c}$ and d, the differences correlated more strongly with gravity than bathymetry. The accuracy of the GGM prediction in Test Area \#1 was within the range of $20 \sim 40 \mathrm{~m}$, due to standard deviation agreement at $35.8 \mathrm{~m}$.

Figure $7 \mathrm{a}$ denotes the bathymetric model of GGM; Table 3 denotes the statistics and correlation coefficients

\section{Test Area \#1}

(a)

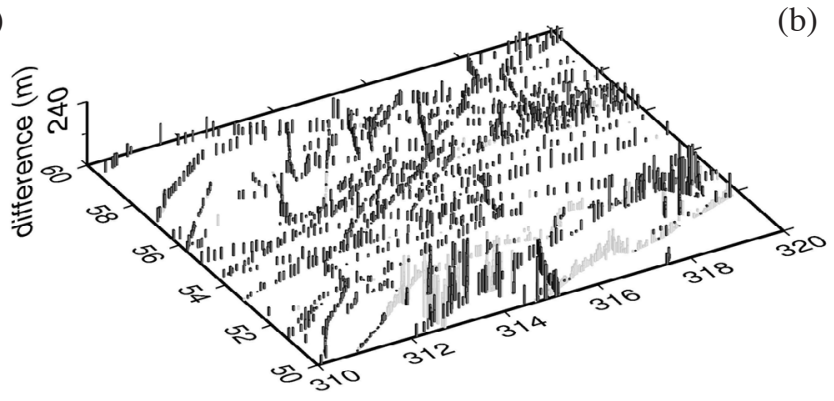

(c)

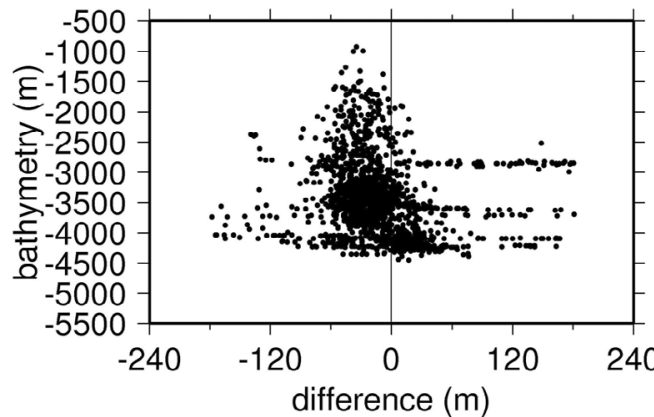

(b)

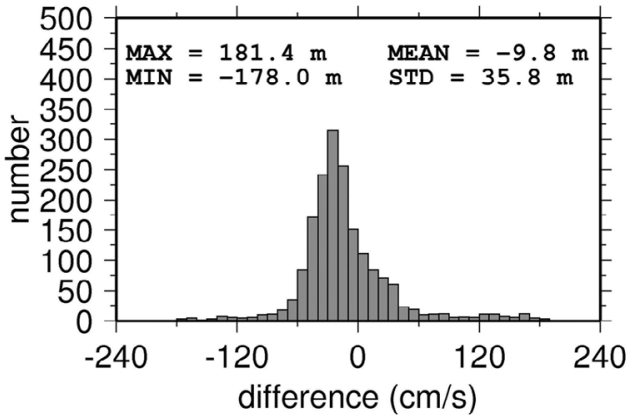

(d)

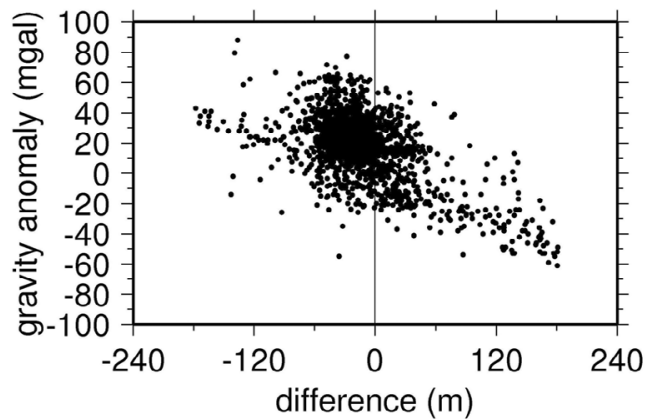

Fig. 6. Test Area \#1. (a) Bathymetry differences between GGM model and NGDC shipborne depths at locations of shipborne tracks; dark-gray and light-gray bars indicate positive and negative differences, respectively; (b) histogram of differences; (c) the relationship between the differences and bathymetry; and (d) the relationship between the differences and gravity anomaly.

\section{Test Area \#2}

(a) GGM

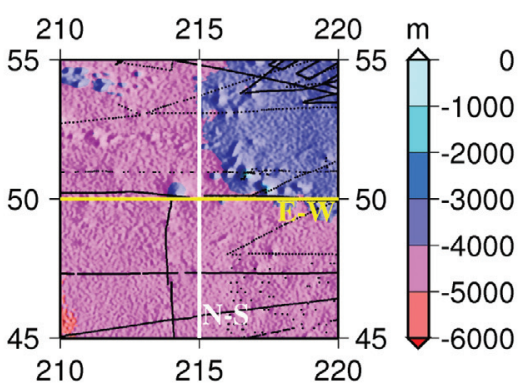

(b) GGM-ETOPO1

(c) GGM-NGDC

(d) ETOPO1-NGDC

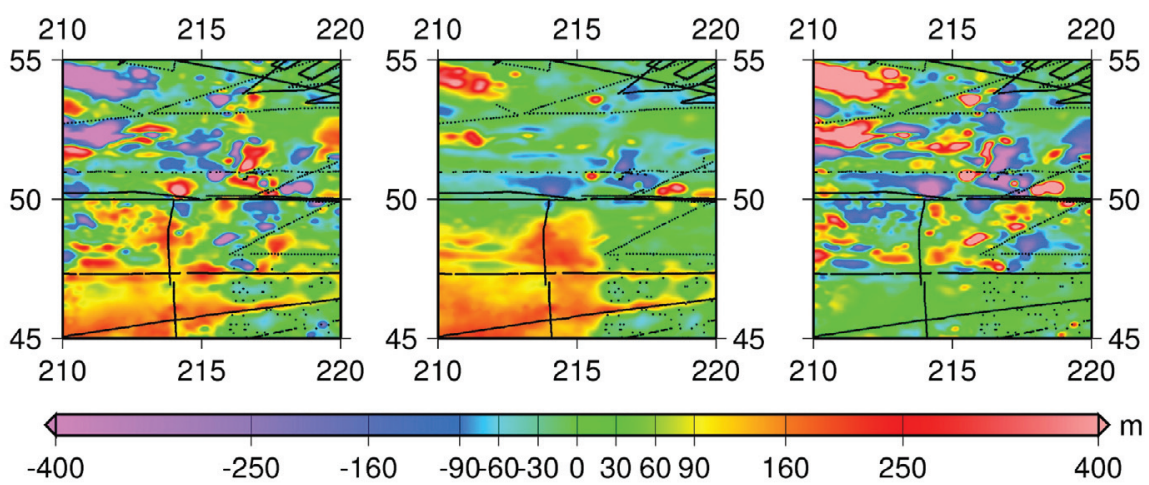

Fig. 7. Test Area \#2. GGM Bathymetric models (a) and differences of bathymetric models between (b) GGM and ETOPO1, (c) GGM and NGDC, and (d) ETOPO1 and NGDC. 
between the three models; Figs. 7b through d represent the differences between the GGM and ETOPO1 models, the GGM and NGDC models, and the ETOPO1 and NGDC models; and, the statistics of their differences are summarized in Table 4. All the figures and tables mentioned above are the results from Test Area \#2. The differences between the GGM and NGDC models and the GGM and ETOPO1 models reached approximate standard deviations of 82.2 and $156.6 \mathrm{~m}$, respectively. The largest differences in Figs. $7 \mathrm{~b}$ and $\mathrm{d}$ can reach $\pm 800 \mathrm{~m}$, similar to the results from Test
Area \#1; however, the differences in Fig. 7c can also reach $400 \sim 500 \mathrm{~m}$, which are 2 times larger than the results from Test Area \#1. The sparse and bed-distributed ship-derived data were the key factor causing the huge differences in Test Area \#2.

Figure 8 denotes the north-south and east-west profiles the GGM, ETOPO1 and NGDC models. The north-south and east-west profiles are along the longitude of $145^{\circ} \mathrm{W}$ and the latitude of $50^{\circ} \mathrm{N}$, respectively. Large differences are found between GGM and ETOPO1 profiles.

Table 3. Comparisons of statistics and correlation coefficients between the GGM, ETOPO1, and NGDC bathymetric models in Test Area \#2 (unit: meter).

\begin{tabular}{cccccccc}
\hline & & & & & \multicolumn{3}{c}{ Correlation Coefficient } \\
\cline { 5 - 8 } Model & Max & Min & Mean & Std Dev & GGM & ETOPO1 & NGDC \\
\hline GGM & -949.4 & -5080.9 & -4277.8 & 426.2 & - & 0.92 & 0.98 \\
ETOPO1 & -53.0 & -5379.0 & -4283.5 & 484.3 & 0.92 & - & 0.92 \\
NGDC & -871.3 & -5252.1 & -4293.7 & 450.2 & 0.98 & 0.92 & - \\
\hline
\end{tabular}

Table 4. Statistics of differences (in m) between GGM and ETOPO1, GGM and NGDC, ETOPO 1 and NGDC in Test Area \#2.

\begin{tabular}{ccccc}
\hline Models & Max & Min & Mean & Std Dev \\
\hline GGM - ETOPO1 & 311.4 & -896.4 & 10.6 & 156.6 \\
GGM - NGDC & 471.0 & -239.7 & 36.8 & 82.2 \\
ETOPO1 - NGDC & 818.3 & -278.6 & 18.3 & 177.7 \\
\hline
\end{tabular}

Test Area \#2

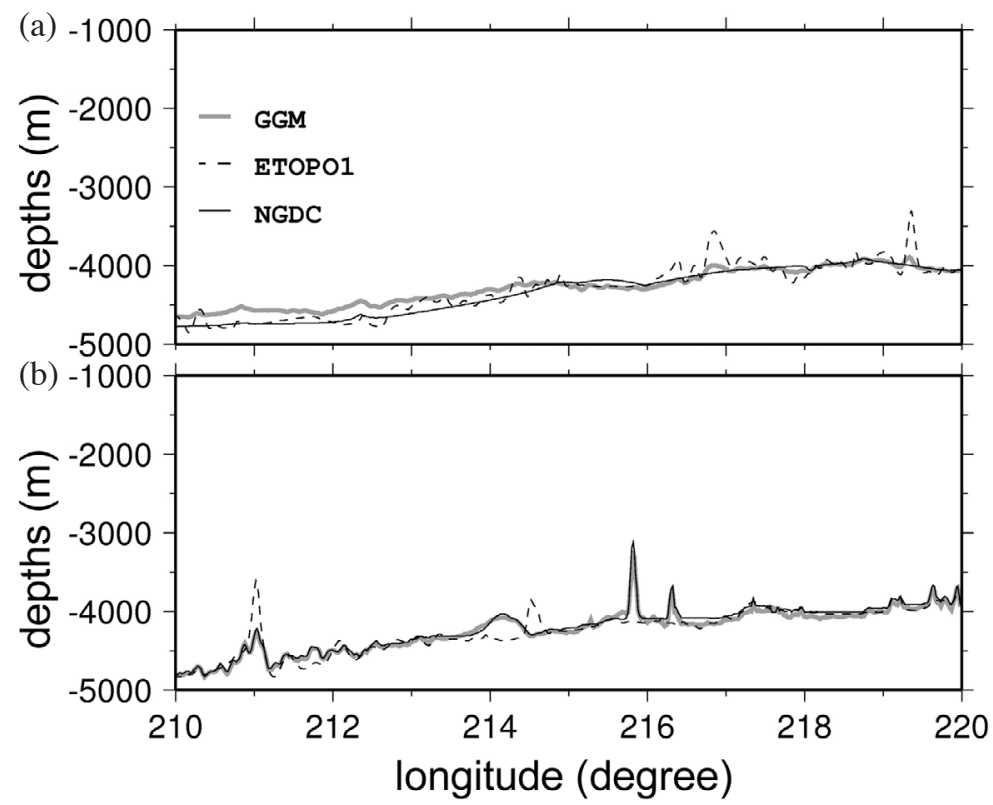

Fig. 8. Test Area\#2. Comparisons for bathymetry along the (a) longitude of $145^{\circ} \mathrm{W}$ and (b) latitude of $50^{\circ} \mathrm{N}$. 
The differences between the GGM model and the shipderived depths at locations of the shipborne tracks are shown in Fig. 9a. The statistics are summarized in Fig. 9b. Compared to Test Area \#1, the differences were greater. There were huge differences with almost the same quantities over the south. The relationships between the differences and the bathymetry and gravity are presented in Figs. $9 \mathrm{c}$ and d, respectively. The differences exhibited better correlation with gravity than bathymetry, the same as Test Area \#1. However, accuracy of the range of $20 \sim 40 \mathrm{~m}$ for the GGM prediction was not achieved in Test Area \#2, due to a standard deviation of $50.4 \mathrm{~m}$.

In general, the GGM predicted bathymetric model in Test Area \#1 was more accurate than in Test Area \#2, and the accuracy of the GGM prediction at the range of $20 \sim 40$ $\mathrm{m}$ was only obtained in Test Area \#1. Because the differences of the variations of bathymetry and gravity in the two test areas were not large, the reason why GGM performed well in Test Area \#1 was due to a more even distribution of shipborne measurements. Overall, GGM is a method which can reflect significant shipborne features due to the relative small differences in Figs. $4 \mathrm{~b}$ and $6 \mathrm{~b}$.

In order to compare the predicted density contrasts to assume $\left(1.64 \mathrm{~g} \mathrm{~cm}^{-3}\right)$, we divided the bathymetry results using different density contrasts into four cases. The assumed density contrasts used in Test areas \# 1 and 2 are cases 1 and
2, respectively; predicted density contrasts $1.47 \mathrm{~g} \mathrm{~cm}^{-3}$ for Test area \# 1 and $1.30 \mathrm{~g} \mathrm{~cm}^{-3}$ for Test area \# 2 are cases 3 and 4 , respectively. Table 5 lists the statistics of the differences between GGM models and NGDC shipborne depths for the four cases. The differences in case 1 are relatively larger than in case 2 . The case using predicted density contrast obviously exhibits an improvement of approximately $3 \mathrm{~m}$ in Test Area \#1. For the Test Area \#2, the results in case 4 are also significantly better than in case 3 . Case 4 considering predicted density contrast enhances the accuracy of approximately $4 \mathrm{~m}$. The comparisons imply that the influence of density contrasts on GGM is remarkable and unavoidable.

In summary, although GGM with properly estimated density contrasts can be effective in predicting large-scale bathymetric coverage from limited shipborne measurements, sparse shipborne measurements can be still a problem for GGM predictions. Furthermore, the consideration of predicted density contrast is necessary for GGM

\section{CONCLUSIONS}

The downward continuation (DWC) method was used to determine the effective density contrast between the seawater and the ocean bottom topographic mass, in order to accurately estimate bathymetry using the gravity-geologic

\section{Test Area \#2}

(a)

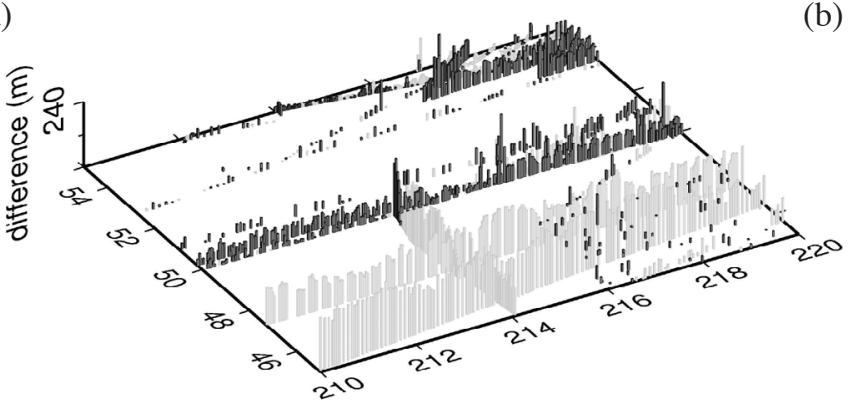

(c)

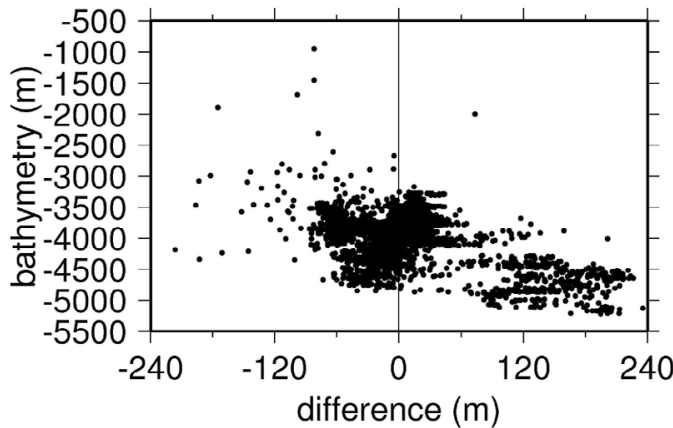

(b)

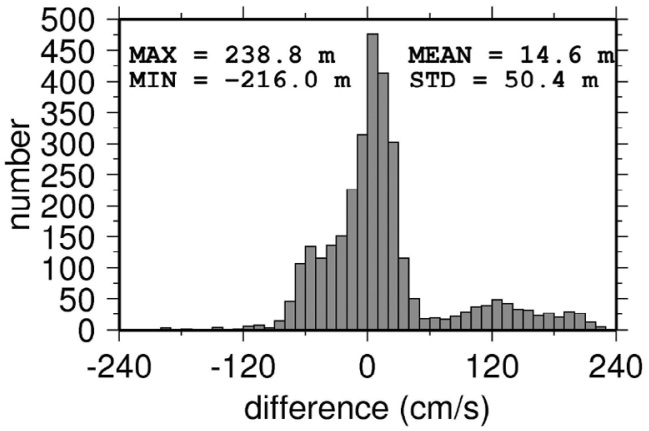

(d)

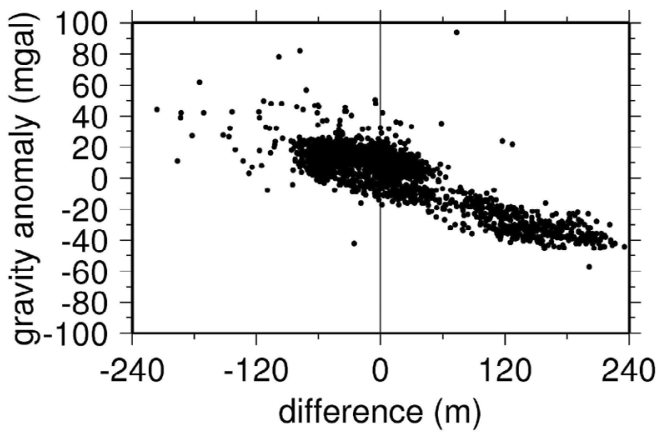

Fig. 9. Test Area \#2. (a) Bathymetry differences between GGM model and NGDC shipborne depths at locations of shipborne tracks; dark-gray and light-gray bars indicate positive and negative differences, respectively; (b) a histogram of differences; (c) the relationship between the differences and bathymetry; and (d) the relationship between the differences and gravity anomaly. 
Table 5. Statistics of differences (in $\mathrm{m}$ ) between the GGM model and NGDC shipborne depths at locations of shipborne tracks for the different density contrasts.

\begin{tabular}{ccccccc}
\hline Case & Test Area & density contrasts $\left(\mathbf{g ~ c m}^{-3}\right)$ & Max & Min & Mean & Std ev \\
\hline 1 & $\# 1$ & 1.64 (assumed) & 177.5 & -189.2 & -10.3 & 38.2 \\
2 & $\# 2$ & 1.47 (predicted) & 181.4 & -178.0 & -9.8 & 35.8 \\
3 & $\# 1$ & 1.64 (assumed) & 249.1 & -204.7 & 16.8 & 54.2 \\
4 & $\# 2$ & 1.30 (predicted) & 238.8 & -216.0 & 14.6 & 50.4 \\
\hline
\end{tabular}

method (GGM) in two study areas. The methodology of density contrast determination was based on DWC filtered by a Gaussian filter and carried out by the FFT technique.

Density contrasts of 1.47 and $1.30 \mathrm{~g} \mathrm{~cm}^{-3}$ were estimated by DWC for Test Areas \#1 and \#2, respectively. The differences between the GGM and NGDC bathymetric models were much smaller than those between the GGM and ETOPO1 models in the two test areas. The standard deviations of the differences along the shipborne tracks between the GGM and NGDC models in Test Areas \#1 and \#2 were 35.8 and $50.4 \mathrm{~m}$, respectively. The differences between the GGM and NGDC models along shipborne tracks were more strongly correlated with gravity anomalies than bathymetry in the test areas. It is shown that accuracy of under $40 \mathrm{~m}$ for the GGM prediction can be obtained in Test Area \#1 with comparisons to shipborne depths. The GGM prediction in Test Area \#1 turned out to be more accurate than in Test Area \#2, due to denser and better distributed shipborne measurements in Test Area \#1, resulting in a better shortwavelength gravity field. Furthermore, the consideration of predicted density contrast can make an enhancement of approximately $3 \sim 4 \mathrm{~m}$ for the GGM.

The bathymetric models predicted by GGM could be used globally to improve the recent bathymetry grids. Moreover, they are expected to aid geophysical and oceanography applications, particularly in remote areas such as the Arctic Ocean. However, a better bathymetric model should be improved by making a new solution that incorporates more new ship data and high-resolution regional and local surveys.

Acknowledgements Elements of this study were supported by COMPAC Project (PE10030) from the Korea Polar Research Institute.

\section{REFERENCES}

Adams, J. M. and W. J. Hinze, 1990: The gravity-geologic technique of mapping buried bedrock topography. In: Ward, S. H. (Ed.), Geotechnical and Environmental Geophysics, Investigations in Geophysics Series 5, Society of Exploration Geophysicists, 99-105.

Amante, C. and B. W. Eakins, 2008: ETOPO1 1 arc-minute global relief model: Procedures, data sources and anal- ysis, National Geophysical Data Center, NOAA, US Department of Commerce, Boulder, CO.

Bhaskara Rao, D., M. J. Parakash, and N. Ramesh Babu, 1990: 3D and 2 1/2 D modelling of gravity anomalies with variable density contrast. Geophys. Prospect., 38, 411-422, doi: 10.1111/j.1365-2478.1990.tb01854.x. [Link]

Blakely, R. J., 1995: Potential Theory in Gravity and Magnetic Applications. Cambridge University Press, UK.

Chai, Y. and W. J. Hinze, 1988: Gravity inversion of an interface above which the density contrast varies exponentially with depth. Geophysics, 53, 837-845, doi: 10.1190/1.1442518. [Link]

Chandler, V. W., 2000: An investigation of bedrock surface topography using the gravity-geologic method, Mower County, Minnesota. In: Mossler, J. H. (Project Manager), Contributions to the Geology of Mower County, Minnesota, Minnesota Geological Survey Report of Investigations, 50, 83-102.

Cordell, L., 1973: Gravity analysis using an exponential density-depth function - San Jacinto Graben, California. Geophysics, 38, 684-690, doi: 10.1190/1.1440367. [Link]

Forsberg, R., 1984: A study of terrain reductions, density anomalies and geophysical inversion methods in gravity field modeling. Technical Report, Department of Geodetic Science and Surveying, Ohio State University, Columbus, USA.

Heiskanen, W. A. and H. Moritz, 1967: Physical Geodesy. W. H. Freeman \& Co. Ltd., San Francisco and London, 364 pp, doi: 10.1007/BF02525647. [Link]

Hsiao, Y. S., 2007: Modeling Taiwan geoid using airborne, surface gravity and altimetry data: Investigations of downward/upward continuations and terrain modeling techniques. Ph.D. Thesis, Department of Civil Engineering, National Chiao Tung University, Hsinchu, Taiwan.

Hsiao, Y. S. and C. Hwang., 2010: Topography-assisted downward continuation of airborne gravity: An application for geoid determination in Taiwan. Terr. Atmos. Ocean. Sci., 21, 627-637, doi: 10.3319/TAO.2009.07. 09.01(T). [Link]

Hwang, C., 1999: A bathymetric model for the south Chi- 
na Sea from satellite altimetry and depth data. Mar. Geodesy, 22, 37-51, doi: 10.1080/014904199273597. [Link]

Hwang, C., C. G. Wang, and Y. S. Hsiao, 2003: Terrain correction computation using Gaussian quadrature. Comput. Geosci., 29, 1259-1268, doi: 10.1016/j.cageo. 2003.08.003. [Link]

Ibrahim, A. and W. J. Hinze, 1972: Mapping buried bedrock topography with gravity. Ground Water, 10, 18-23, doi: 10.1111/j.1745-6584.1972.tb02921.x. [Link]

Kim, J. W., R. R. B. von Frese, B. Y. Lee, D. R. Roman, and S. J. Doh, 2011: Altimetry-derived gravity predictions of bathymetry by the gravity-geologic method. Pure Appl. Geophys., 168, 815-826, doi: 10.1007/s00024010-0170-5. [Link]

Mossler, J. H., 1998: Geologic Atlas of Mower County, Minnesota, C-11, Part A, Plate 5, Depth to bedrock and bedrock Topography. Minnesota Geological Survey, University of Minnesota.

Nagarajan, R., 1994: Gravity-geologic investigation of buried bedrock topography in northwestern Ohio. Master Thesis, Department of Geological Sciences, The Ohio State University, Columbus, OH, USA.

Parker, R. L., 1977: Understanding inverse theory. Ann. Rev. Earth Planet. Sci., 5, 35-64, doi: 10.1146/annurev. ea.05.050177.000343. [Link]

Pavlis, N. K., S. A. Holmes, S. C. Kenyon., and J. K. Factor, 2008: An earth gravitational model to degree 2160:
EGM2008. Presentation given at the 2008 European Geosciences Union General Assembly, Vienna, Austria, April 13-18.

Ramillien, G. and A. Cazenave, 1997: Global bathymetry derived from altimeter data of the ERS-1 geodetic mission. J. Geodyn., 23, 129-149, doi: 10.1016/S0264-37 07(96)00026-9. [Link]

Silva, J. B. C., D. C. L. Costa, and V. C. F. Barbosa, 2006: Gravity inversion of basement relief and estimation of density contrast variation with depth. Geophysics., 71, J51-J58, doi: 10.1190/1.2236383. [Link]

St John, V. P. and R. Green, 1967: Topographic and isostatic corrections to gravity surveys in mountainous areas. Geophys. Prospect., 15, 151-162, doi: 10.1111/j.13652478.1967.tb01778.x. [Link]

Strykowski, G., F. Boschetti, and G. Papp, 2005: Estimation of the mass density contrasts and the 3D geometrical shape of the source bodies in the Yilgarn area, Eastern Goldfields, Western Australia. J. Geodyn., 39, 444460, doi: 10.1016/j.jog.2005.04.004. [Link]

Tikhonov, A. N. and V. Y. Arsenin, 1977: Solutions of IllPosed Problems, Winston-Wiley, New York.

Wessel, P. and W. H. F. Smith, 1995: New version of the generic mapping tools released. Eos Trans. AGU, 76, 329.

Wild-Pfeiffer, F., 2008: A comparison of different mass elements for use in gravity gradiometry. J. Geodesy, 82, 637-653, doi: 10.1007/s00190-008-0219-8. [Link] 